\title{
Diálogos com o real: uma balbúrdia na Barra Funda
}

\section{Resumo}

O presente artigo origina-se do núcleo central de minha pesquisa de doutoramento intitulada "Barafonda: Dimensão Política e Produto Artístico". Barafonda, espetáculo encenado e concebido pela Cia. São Jorge de Variedades versa sobre a memória do bairro Barra Funda e da cidade de São Paulo. Neste contexto, em torno da relação teatro e realidade, proponho a noção de "Diálogos com o Real" como instrumento central à análise que aqui me proponho a realizar.

Palavras-chaves: Barafonda; Cia. São Jorge de Variedades; Diálogos com o Real.

\section{Abstract}

The present paper is originated from the central core of my doctoral research which was named "Barafonda: Political Dimension and Artistic Product". Barafonda is a theater play created and performed by Cia. São Jorge de Variedades - Brazilian Theater Company from São Paulo - which brings out and explores Barra Funda's neighborhood as well as São Paulo's memories. In this context, coming around the relation between theater and reality, I propose the notion of "Dialogues with the Real" as a main tool for the analysis which I intend to accomplish.

Key-words: Barafonda; Cia. São Jorge de Variedades; Dialogues with the Real.

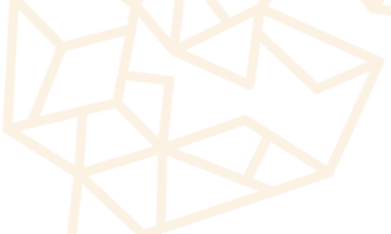

Recentemente encontrei meu espectador Na rua poeirenta

Ele segurava nas mãos uma máquina britadeira. Bertolt Brecht

Com quatro horas de duração, o espetáculo Barafonda apresenta-se na rua e na sede da Cia São Jorge de Variedades. Seu trajeto começa na Praça Marechal Deodoro, percorre as ruas do bairro Barra Funda, adentra a sede do grupo, continua sua caminhada atravessando a linha do trem e termina em um local que alude à memória do passado do bairro: casarões geminados, ausência de trânsito de carros, tudo iluminado por tochas e lampiões em um ar nostálgico e singelo em meio à confusão da cidade.

\footnotetext{
1 Professora de Encenação, Iluminação Cênica e Elementos Plásticos da Cena no Curso de Teatro da Universidade Federal de São João Del Rei - UFSJ. Doutoranda em Teatro pelo Programa de Pós-Graduação em Artes Cênicas da Universidade Federal do Estado do Rio de Janeiro - UNIRIO. Mestre em Teatro pelo Programa de Pós-Graduação em Artes Cênicas da Universidade Federal do Estado do Rio de Janeiro - UNIRIO (2009). Bacharel em Direção Teatral com Graduação em Artes Cênicas na Universidade Federal de Ouro Preto - UFOP (2006).
} 
A rua traz para Barafonda o inusitado, ao recusar uma sala fechada e neutra, onde se pode construir para o espectador todos os aspectos de uma ficção. O espetáculo parte para um ambiente já carregado de aspectos simbólicos, históricos e políticos próprios. A rua manifesta suas ambiguidades na essência do que significa ser público - político -; lugar onde os comportamentos seguem a orientação de sujeitos em comunidade, que deixam os meandros do particular e do doméstico, assumindo as relações intersubjetivas do espaço partilhado. Veremos que essa noção do espaço público, e as relações intersubjetivas relativas a ele, em nossa contemporaneidade, é posta em pauta seja pela crescente privatização dos espaços públicos - shoppings, condomínio, etc. -, seja pelo violento processo de limpeza e gentrificação do espaço urbano. Percebemos, portanto, que a rua, apesar de sua natureza pública, sofre um crescente controle de seus espaços e, esse controle, ao invés de privilegiar os meios de convívio, muitas vezes contrapõem-se a eles, privilegiando os interesses privados geridos pelo capital.

Ao tratar a rua como uma ambiência, pretende-se buscar uma apreciação que não se anseia como sistemática ou histórica, mas salienta-se o efeito de diálogo de alguns aspectos históricos do pensamento estético e político no que diz respeito ao teatro. Sabemos que a noção de ambiente é uma noção cara ao movimento naturalista no teatro, na virada do século XIX para o XX; e este movimento nos interessa por dois aspectos: 1) a noção de ambiência e 2) a de consciência histórica e luta de classes.

A noção de ambiência afirma-se principalmente no naturalismo francês. Temos em Antoine e Zola figuras que não só teorizam, mas também colocam em prática seus preceitos. O cientificismo está no alicerce do naturalismo francês, dando passagem à observação empírica e, nessa perspectiva, o naturalismo francês pode ser considerado como uma representação crua do real. A busca da verdade que é fundamentada pelo observável (BORNHEIM, 1992, p. 17-22).

O naturalismo pensado nestes moldes atrelava-se a uma cartilha teórica à qual cabe questionar até que ponto Ihe eram fiéis as peças, ou mesmo, se era possível lhe ser fiel. Não nos esqueçamos do momento histórico no qual a encenação teatral ganha status junto à obra literária, ou seja, o teatro passa a ser entendido não apenas como literatura - embora ainda esteja a ela atrelada -, mas como um conjunto composto pelo texto e sua materialização em cena. Exatamente a prova deste novo entendimento está no fato do momento histórico de instauração do naturalismo no teatro - passagem do 
século XIX para o XX - ser considerado como o momento histórico do surgimento do encenador, figura imprescindível para o estabelecimento do teatro moderno. Na França destaca-se a figura de Antoine, apontado como o primeiro diretor teatral na acepção moderna do termo. Sarrazac, no texto "Realismo e encenação moderna: o trabalho de André Antoine" (2004), nos chama a atenção aos métodos empregados pelo diretor, nos quais mais do que a encenação científica da verdade, busca-se "uma interrogação filosófica sobre a verdade" (SARRAZAC, 2004, p. 122). Neste sentido, a cena passa a enquadrar a realidade contemporânea, dando ênfase aos elementos sociais já arrebatados pela literatura, lançando sobre o palco os conflitos sociais de operários, de camponeses, dos subúrbios, compreendendo o homem como fruto de seu meio.

A teoria do ambiente e suas intermináveis descrições do meio, tão importantes ao romance, traduziam-se no palco em minuciosas estruturas de cenário, construídas anteriormente aos próprios personagens em cena. Tal minúcia trouxe ao naturalismo francês uma comparação com a visão fotográfica, de pura reprodução do real, tornando estética e estática a visão histórica ali contida. Porém, os princípios do naturalismo francês alcançam outras perspectivas pela Europa, por exemplo, na Alemanha veremos que a inspiração trazida por Antoine fecunda perspectivas importantes para o teatro político.

Em solo germânico a hegemonia positivista, com Mach e Avenarius, durou apenas alguns escassos anos, e logo voltou a ceder seu lugar ao que vinha seduzindo a inteligência alemã desde o século XVIII: os processos históricos e o aparecimento da consciência histórica. E é precisamente em função desses conceitos que se verifica o desempenho de um Otto Brahm. O contexto da doutrina de Zola e Antoine se faz sem dúvida aqui e ali presente, mas como um todo a dramaturgia naturalista alemã embrenha-se por horizontes mais amplos. Abandona-se então a estaticidade fotográfica dos começos franceses a favor da historicidade dos seus conteúdos (BORNHEIM, 1992, p. 19).

A inserção no contexto histórico traz a responsabilidade do sujeito em determinada sociedade, seja ele inserido ou fruto da mesma. Em ambos os casos, a crítica social precipita-se e dá voz a situações e a camadas sociais nunca antes contempladas. Neste sentido, podemos chamar a arte da consciência histórica de arte política, na medida em que desenha e questiona a formação da comunidade, que dá voz e espaço para uma camada desprezada no campo do estético pela tradição ocidental.

Se pensarmos na ideia de "Partilha do Sensível," proposta por Jacques Rancière (2005), veremos que essa reconfiguração do campo do estético se dá não apenas pela apresentação de uma camada social popular, mas também pelos mecanismos que as 
tornam sensíveis e visíveis, pela sua disposição perante a comunidade. Neste ponto, o naturalismo e sua abertura para a visão de comunidade tornam-se importantes como precedentes de um teatro político de consciência histórica. Precedentes na medida da importância de se pensar o teatro político não apenas como uma temática, mas como uma operação no campo do sensível que inclui sua forma cênica. Neste sentido, abrem-se outras experiências históricas, importantes para nossa reflexão, que incluem o debate entre o teatro e o real em camadas da experiência cênica que dialogam com o espetáculo Barafonda.

Uma das experiências históricas que podemos resgatar para refletir sobre a questão é o trabalho de Erwin Piscator. O diretor desenvolve um estilo de teatro, por ele intitulado "Teatro Político" (1968), que fez uso de fragmentos da realidade através da incorporação de aparatos técnicos documentais, criando um ambiente histórico de cunho social. Um exemplo marcante do estilo de Piscator traduz-se no espetáculo, um "drama documentário", Apesar de tudo: "todo o espetáculo foi uma única montagem de autêntico discurso, redação, recortes de jornal, conclamações, folhetos, fotografias e filmes da guerra e da revolução, de personagens e cenas históricas" (PISCATOR, 1968, p. 82). O projeto inicial do espetáculo contava com dois mil participantes em um vale de montanhas em Gosen, mas realiza-se no Grosses Schauspielhaus, a grande casa de espetáculos construída por Max Reinhardt, com duzentos participantes. Neste espetáculo, o teatro político praticado por Piscator pretende-se como um teatro de grandes acontecimentos, contendo o desejo de promover uma unidade entre palco e plateia.

\footnotetext{
Na noite do espetáculo, milhares de espectadores lotaram a Grande Casa. Todos os lugares disponíveis estavam ocupados, escadas, corredores, passagens. A euforia provocada pelo fato de poderem assistir ao espetáculo dominava aquelas criaturas. Notava-se, em face do teatro, uma inaudita disposição só encontrável no proletariado.

Mas imediatamente a disposição passou a uma efetiva atividade: a massa incumbiu-se da direção artística. Os que lotavam a casa tinham, em sua maioria, vivido ativamente aquela época que era realmente o seu destino, a sua própria tragédia, a se desenrolar diante de seus olhos. O teatro, para eles, transformara-se em realidade. Em pouco tempo cessou de haver um palco e uma plateia, para começar a existir uma só grande sala de assembleia, um único grande campo de luta, uma única grande demonstração. Foi essa unidade que, naquela noite, provou definitivamente a força de incitamento do teatro político (PISCATOR, 1968, p. 83-84).
}

Na experiência acima descrita, o público deixa de ser uma simples reunião de indivíduos para configurar-se como um grupo, no qual as opiniões individuais se guiam no sentido da formação de uma opinião pública. 
Neste contexto, podemos também nos remeter a uma experiência russo- soviética, pós-revolução de 1917 que, fundada na experiência do real, remonta um episódio histórico, unindo plateia e palco. Trata-se do espetáculo de massa: $A$ tomada do Palácio de Inverno, encenada por Kugel, Petrov e Evreinoff, em 7 de novembro de 1920, na ocasião do terceiro aniversário da revolução de outubro. O espetáculo aconteceu em Petrogardo, exatamente no cenário dos fatos históricos. Cerca de cem mil homens participaram da ação e, entre eles, centenas haviam participado de fato, três anos antes, dos acontecimentos ali narrados, reconstituindo-os não apenas a partir de dados documentais, mas também das experiências concretas, da memória. Exemplo de uma encenação que uniu passado e presente em um jogo teatral no qual não se dava mais a separação entre espectadores e atores, estando os espectadores no centro dos acontecimentos:

\begin{abstract}
Regimentos inteiros foram mobilizados: marinheiros, membros do Partido, jovens comunistas [...], sinaleiros, telefonistas, carpinteiros, técnicos, armadores, arquitetos, pintores publicistas, homens de letras, artistas de teatro e de circo, regentes. São mobilizados canhões, metralhadoras, caminhões e até o encouraçado Aurora, que em 1917 havia bombardeado os exércitos do Governo Provisório. (GOLRFINKEL, apud GARCIA, 2004, p. 26).
\end{abstract}

O teatro e seu diálogo com o real, nas diversas experiências históricas, busca seu sentido em relação à história. Vincula o homem - tanto aquele que pertence ao palco quanto aquele que pertence à plateia - a um lastro histórico e social. Nesses exemplos, a relação entre teatro, história e público dá-se, mesmo partindo do pressuposto da integração palco e plateia, por uma via de apresentação do fato histórico, a partir da cena, e aprovação ou não, daquele fato, por parte do público - seja na participação direta ou apenas na sua apreciação. Tal postura, como nos assinala Bernard Dort (1997), traz, em relação à história e à cena, uma questão em si mesma, ou seja, a história é dada de forma engessada, uma história representada, portanto, que já está morta ou superada. Na obra de Bertolt Brecht, a relação teatro/história/público será intensificada e problematizada. Neste sentido, o teatro épico trabalha a história através de um processo de compressão, propondo uma relação dialética entre o palco, o público e a história. Na obra de Brecht, o centro da peça não se encontra nela mesma, mas fora, na relação estabelecida entre a plateia e a história. Louis Althusser (1968) assinala diversas reformas na técnica teatral de Brecht, que devem ser entendidas, e isso é importante, como uma revolução da prática teatral. Esta se deu por deslocamentos no conjunto da encenação tanto em diferentes acepções da relação público/cena, atores/público, teatro/história: 
O resultado de todos esses deslocamentos produz uma nova relação entre o espetáculo e o público. É uma relação deslocada. Brecht exprimiu esse efeito de deslocamento como efeito- $V$, no próprio público, como o fim da identificação. O público deve deixar de se identificar com o que a cena faz ver, ele deve se encontrar em posição crítica, e tomar o seu próprio partido, julgar, escolher e se decidir. A peça não decide nada por ele. A peça não é uma roupa pronta a vestir. A peça não é uma roupa. O público deve cortar sua própria roupa com o tecido da peça, ou ainda com os pedaços de tecido que a peça lhe dá. Pois, não há nada na peça roupa pronta. Em termos simples, não há heróis (ALTHUSSER, 2007, p. 60).

Nesta relação entre teatro e realidade e sua representação, constatamos - para continuar com Althusser - um deslocamento do desejo de realidade diretamente ligado à ideia de ilusão cênica, apreciada por meio de um aparato cênico que favorecia tais princípios, para a leitura de representação da realidade cênica na quebra da ilusão e instauração da teatralidade, através do desvelamento deste mesmo aparato cênico, do qual se serve a ilusão. A crítica ao modelo tradicional se deu em seu próprio espaço, ou seja, o palco italiano, e utilizando-se também de seu aparato técnico como crítica e linguagem. Porém, a revolução proposta por Brecht não é impulsionada apenas por uma questão de estilo ou estética, a passagem da forma dramática para a forma épica é motivada por uma nova análise da sociedade, o indivíduo não está mais em oposição a outro indivíduo, mas a um sistema econômico. Para tal, a cena, em vez de corporificar as ações, relata-as, transformando o espectador em um observador que formula um senso crítico sobre aquilo que assiste. Desenvolve vários mecanismos formais que fragmentam e comentam a cena, transformando a experiência passiva da assistência em uma atitude ativa por meio da tomada de consciência. A fragmentação da dramaturgia, tornando cada cena autônoma; a entrada do narrador, que expõe e comenta diferentes pontos de vista; e o fim da linearidade temporal são alguns dos elementos novos que surgirão neste novo gênero. Diferente da relação do teatro dramático, que coloca o espectador confortavelmente em uma relação frontal para admirar a ficção, o teatro épico se coloca no palco para observar e criticar a vida estabelecida para além dele. Dentro deste contexto, tanto o espaço quanto o material cênico convencional utilizado na encenação trazem a dimensão da crítica que é feita a um sistema estabelecido, sistema este que deve ser desvelado e manipulado de forma a desnaturalizar aquilo que foi convencionado como natural e, desta maneira, pensar novas possibilidades de relações humanas e sociais.

A experiência do teatro épico no século XX, na intenção de um espectador ativo, promove um movimento de aproximação entre público e obra, trazendo uma premente 
preocupação com a condição de que se está sujeito e, consequentemente, tornando o espectador em um dos eixos da criação. Este movimento traz como consequência uma aproximação entre arte e vida, pois cada vez mais o público envolve-se com a obra, sendo "trazido" para dentro dela. A relação entre o teatro e o real, levando-se em conta o fenômeno teatral, é valorizada e intensificada, ou seja, valoriza-se a configuração da linguagem artística que conta com a presença concomitante de ator e público; com as prerrogativas do corpo e da presença que jogam com o real; com o acontecimento presente que elabora e exerce uma tensão entre a realidade e a ficção. Todas estas são premissas que trazem algo de específico para a arte, tencionando e problematizando mais ainda a relação entre teatro e realidade. Um bom exemplo disso é a percepção de como o conceito de performance passa a operar dentro da noção de teatro. Josette Féral (2008) nos chama a atenção ao desejo político contido neste conceito que pretende reinscrever a arte no domínio do cotidiano, do comum. Portanto, a "expansão da noção de performance sublinha" "o fim do conceito de teatro praticado há algumas décadas" (FERAL, 2008, p. 199). O teatro que almeja a aproximação entre vida e arte espera, portanto, um espectador que interaja com o espetáculo. Entra em cena a noção de acontecimento cênico, onde o espetáculo propicia uma troca desenvolvendo-se na busca de sensações e experiência. Tal noção, diretamente relacionada à entrada da noção de performance no teatro, pode ser ressaltada nas artes cênicas a partir da década de 1960, como um movimento que originalmente parte das artes plásticas, valorizando a experiência entre público e arte como um acontecimento efêmero e único, passível de ser captado a partir de um movimento relacional entre as partes. Neste ponto de vista, o real dentro da arte configura-se não mais como uma representação, mas dentro de um processo de vivência e experiência.

Neste contexto, teóricos como Josette Féral (2008) e Hans-Thies Lehmann (2007) ressaltam a presença do corpo no teatro contemporâneo como ferramenta política fundamental. No caso da análise proposta ao espetáculo Barafonda, na qual se pretende filiá-lo a um teatro político, precisamos adicionar ao elemento da presença aquilo que procuramos ressaltar até aqui, quando refletimos sobre as diferentes acepções e usos do real em algumas experiências do teatro que se almeja político. Trata-se da presença da relação teatro/público/história, em um movimento crescente de preocupação e inclusão do público, preocupação essa que passa por uma conscientização, chegando a uma participação efetiva como agente criador dentro da obra. 
Barafonda nos convida a participar conjuntamente da construção de sentido daquilo que assistimos. O conjunto da encenação - que abrange a textualidade, a corporeidade, a plasticidade, a musicalidade - une-se ao espaço do inusitado na encenação. A quantidade de informações que a rua oferece é imensurável, agravando-se pelo dia e horário escolhido para a apresentação: sextas-feiras das 15 horas às 19 horas, dia e horário em que a cidade de São Paulo encontra-se em "pleno vapor", tanto no funcionamento do comércio e serviços em geral quanto no crescimento da chamada "hora do rush". Há um espectro semântico que o espaço por si só traz à obra, que contamina tanto o espetáculo como os espectadores. $O$ conjunto de sentidos que se pode extrair da rua corrobora para o intrincado semântico da obra, e o mais impressionante é que o espetáculo prevê tal fenômeno. Barafonda não se sobrepõe à rua, muito pelo contrário, a quantidade de informações características do lugar fazem parte da obra.

Assistindo-se a várias apresentações, em uma que ocorreu em um sábado feriado, foi visível a "perda" do espetáculo, dependente do ritmo frenético da cidade. Ele depende do trânsito de carros, do barulho, das manifestações vindas dos passantes a favor ou contra, todos esses elementos fazem parte da narrativa, uma polifonia construída a partir das vozes dos artistas, mas também do espaço. Assim podemos entender o espaço da encenação como um dos elementos que dá voz à dramaturgia e, talvez, um dos seus elementos mais fortes, pois, além de representar uma voz marcante da dramaturgia, insere e comunga ficção e público em um só ato. Neste sentido, a rua, no espetáculo Barafonda, não é apenas um pano de fundo, mas também uma ambiência essencial para seu acontecimento:

\begin{abstract}
Atualmente conhecemos bem uma outra modalidade de existência do espaço teatral na representação. Refiro-me aos "espetáculos de percurso" ou, mais amplamente, ao "teatro ambiental" (environment theater, Schechner), ao "teatro da materialidade". Nestes, o lugar (frequentemente não um teatro, mas um edifício ou até uma paisagem que tem uma identidade e uma história alheias ao texto e mesmo a toda a atividade lúdica) não é escolhido para responder a uma ideia preconcebida ou a certas virtualidades do texto e também não é construído ou utilizado para dar conta disso. O espaço é um elemento autônomo e durável da representação que participa da encenação da mesma forma que o texto (ou sua ausência), as mímicas, os movimentos e a declamação dos atores. Ele traz sua identidade, sua história e sua carga de significados. Texto e cena se interferem mutualmente: eles não estão a serviço um do outro, eles não se anulam. Além disso, o lugar, mais que a cena, engloba, frequentemente, até o espectador (DORT, 2013, p. 52).
\end{abstract}

Mesmo que se utilize da rua como ambiência, o espetáculo não deixa, em nenhum momento, de assumir sua teatralidade, aplicando uma lição dada desde Meyerhold e bem-acabada em Brecht: de um teatro que confesse que é teatro; tal 
intersecção percebe-se na maneira como manipula os elementos do real. Um bom exemplo está em seus cenários e adereços, confeccionados com materiais cotidianos e facilmente encontrados descartados pelas ruas, como garrafas de água, sacos de lixo, embalagens de alimentos, como chocolates, biscoitos, etc., mas nada cotidianos em sua conformação. Os figurinos são trocados no decorrer da encenação. No primeiro momento, antes de chegarmos à sede do grupo, a maioria dos atores veste macacões de operários - forte referência ao teatro Agitprop -; na primeira cena, o coro, na praça Marechal Deodoro, usa capas de chuva amarelas lembrando a imagem de garis em dia de chuva. A cor forte do amarelo contrasta com o cinza da cidade, trazendo um estado festivo e, ao mesmo tempo, a imagem de trabalhadores da rua é o uso extracotidiano do corpo e do espaço, instaurando o inusitado no cotidiano do bairro, via elementos do próprio cotidiano.

O espetáculo começa com um prólogo do personagem Rafael Galvez (19071998), artista plástico que viveu no bairro, narrando sua morte, indicando que o espetáculo se inicia pelo fim da história que ali será narrada. Após o prólogo, assistimos à cena de libertação de Prometeu, uma cena narrada pela música de uma banda de rock que se apresenta ao vivo e com a participação de quase todos os atores do grupo, que surgem das ruas atravessando na frente dos carros, fazendo movimentações em um coro teatral liderado pelo personagem Hércules $\mathrm{O}$ que chama atenção na cena, e que será operado durante boa parte do espetáculo, é como os atores se colocam diante da rua, em confronto com a arquitetura, com o trânsito dos carros, marcando a presença do corpo pela forma como o colocam em risco. Isto acontece na apropriação do espaço, quando sobem nos monumentos, atravessam as ruas junto aos carros, representam junto a figuras da rua, que oferecem o inesperado. A valorização da presença do corpo que se coloca em risco é ressaltada por estudiosos do teatro contemporâneo, como é o caso de Sílvia Fernandes, ao analisar o trabalho do Teatro da Vertigem:

\footnotetext{
Um desempenho que agride o espectador pela violenta exposição corporal do ator, mantido nos limites da resistência física e psíquica, são aos espetáculos a contundência de eventos de riscos, de formalização instável, quase fluxos processuais de performatividade, inacabados e atualizados a partir dos vetores referidos, de ocupação espacial de fisicalidade (FERNANDES, 2009, p. 127).
}

No caso de Barafonda, a presença do ator e a ambiência escolhida para a encenação provocam um efeito crítico, e por que não dizer político, quando soma-se a 
esses dois o fator ético da inserção do teatro na realidade. A aproximação com o real, combinada à rejeição da representação realista nos moldes tradicionais e mercadológicos do teatro, está presente na produção teatral de alguns grupos paulistas. Em Teatros do Real (2010), Sílvia Fernandes coloca a questão:

\begin{abstract}
Não por acaso, os grupos mencionados buscam espaços urbanos de uso público para suas apresentações, em geral contaminados de alta carga política e simbólica, além de apresentarem um desvio geográfico de interesses, do centro para as periferias urbanas e nacionais e, especialmente, recusarem-se a funcionar em circuitos fechados de produção e recepção teatral. A autonomia e autorreferência das encenações dos anos de 1980, por exemplo, de alto calibre estético e baixa voltagem política são, dessa forma, substituídas pela vontade explícita de contaminação com a realidade social mais brutal, em geral explorada num confronto corpo a corpo com o outro, o diferente, o excluído, o estigmatizado. [...]

Esse teatro de vivências e situações públicas não pretende, evidentemente, representar alguma coisa que não esteja ali. Ao contrário a tentativa é de escapar do território específico da reprodução da realidade para tentar a anexação dela, ou melhor, ensaiar sua presentificação (FERNANDES, 2010, p. 85).
\end{abstract}

Tal teatro, nomeado por Sílvia Fernandes como esse "teatro de vivências e situações públicas", toma para si dois espectadores diversos: o que está ali para assistir ao espetáculo (espectador teatral) e o que está ali, na rua, na sua rotina diária e encontra-se com o espetáculo (espectador transeunte), podendo parar para assisti-lo, ou não, apenas por um momento, ou toda a apresentação. Os dois espectadores trazem à experiência do espetáculo suas práticas cotidianas: por um lado, o espectador teatral, mesmo na rua, tende a comportar-se como no espaço teatral, segundo suas convenções - não é difícil ver alguns deles incomodados com barulhos e interferências da rua no continuum do espetáculo -, observa e tenta compreender as ações; por outro lado, quem pertence à rua, ou seja, os moradores, transeuntes, comerciantes, moradores de rua, etc., tendem a se comportar de forma habitual - o que também os leva, em casos não pouco raros, a se incomodarem com aquela "balburdia" que Ihes atravessa o caminho. Contudo, percebemos que o espetáculo instaura um desequilíbrio nesses comportamentos habituais, contaminando ambas as partes com o acontecimento cênico, instaurando um estado de "liminaridade", unindo espectadores e habitantes no jogo cênico do olhar e ser olhado, dar sentido e sentir-se, inscrevendo um espaço/tempo extraordinário que invade a vida cotidiana, e instiga a participação ativa do público.

Terminada a cena de libertação de Prometeu somos convidados a seguir uma bicicleta/carro de som que, anunciando contar a história do Bairro, dá início a nossa caminhada. Durante o percurso, o coro, formado por cerca de 20 atores, compõe quadros na malha urbana. São dezenas de quadros instalados nas praças, estabelecimentos, ao 
lado de transeuntes, moradores de rua. Esses quadros direcionam o olhar do público para a cidade, mostrando suas contradições, porém são apenas quadros que não trazem a leitura de um significado direto e racional, mas acionam os domínios sensitivo e afetivo daquele que assiste. Portanto, esses quadros colocam-se ao lado do real, brincando com ele e, com esse jogo, inventam uma nova realidade, revelando a dialética entre o real e aquilo que poderia ser o real. Esse mecanismo, como nos lembra Dort, segue o direcionamento e o entendimento de Brecht, no sentido de situar o palco e plateia na história, sendo ela a responsável pela última palavra, na organização de uma "nova dialética entre o palco, a plateia e a história". Os quadros formados pelos atores remetem a um lirismo, quando, por exemplo, dançam na saída de ar do metrô, e um longo TNT² branco voa, em uma dança leve; contudo, a maioria das imagens nos parece imagens críticas, que se referem ao homem diante da cidade, sua estrutura do consumo e das relações humanas desgastadas. As imagens forçam-nos a olhar para as lojas, bancos, lixeiras, carros e seus motoristas impacientes, moradores de rua, passantes, trabalhadores da área, de forma especial. Quando nos deslocamos para a praça onde começa o espetáculo, passamos por muitos desses lugares e pessoas, mas não reparamos neles. As grandes cidades desenvolvem este potencial. Passamos e olhamos apenas aquilo que nos interessa, ou mesmo nem olharmos para nada, pela pressa e objetividade em chegar a nosso destino. Eis a surpresa desta primeira parte do espetáculo, que nos convida a apreciar o caminho, a olhar cada detalhe e extrair pelo olhar as sensações mais íntimas de nossa história no embate com a história viva do local. Depois desta mirada pelo bairro, nada mais parece habitual, o som e as imagens da cidade se revelam com outras cores e contornos. E, nesta toada, assim como abrimos, encerramos:

\begin{abstract}
Desconfiai do mais trivial, na aparência singelo. E examinai, sobretudo, o que parece habitual. Suplicamos expressamente: não aceiteis o que é de hábito como coisa natural, pois em tempo de desordem sangrenta, de confusão organizada, de arbitrariedade consciente, de humanidade desumanizada, nada deve parecer natural nada deve parecer impossível de mudar. (Poema de Bertolt Brecht - Nada é Impossível Mudar).
\end{abstract}

\title{
Referências bibliográficas
}

ALTHUSSER, Louis. Sobre Brecht e Marx. Crítica Marxista, n. 24, p. 51-62, 2007.

BORNHEIM, Gerd. Brecht: A estética do teatro. São Paulo: Graal, 1992

CIA SÃO JORGE DE VARIEDADES. Roteiro Barafonda. Texto do EspetáculoBarafonda cedido pelos membros da Cia São Jorge de Variedades. 2012.

2 TNT é a sigla para Tecido Não Tecido. Trata-se de um tecido produzido a partir de fibras desorientadas que são aglomeradas e fixadas, não passando pelos processos têxteis mais comuns que são a fiação e a tecelagem (ou malharia). 
DORT, Bernard. O teatro e sua realidade. São Paulo: Perspectiva, 1977.

A representação emancipada. Sala Preta, São Paulo, Escola de Comunicações e Artes, Universidade de São Paulo, v. 13, n. 1, p. 47-55, 2013. DOI: http://dx.doi.org/10.11606/ issn.2238-3867.v13i1p47-55

FÉRAL, Josette. Por uma poética da performatividade: o teatro performativo. Sala Preta, São Paulo, Escola de Comunicações e Artes, Universidade de São Paulo, v. 8, p. 197-209, 2008. DOI: http://dx.doi.org/10.11606/issn.2238-3867.v8i0p197-210

FERNANDES, Sílvia. Teatralidades contemporâneas. São Paulo: Perspectiva, 2009.

GARCIA, Silvana. O teatro da militância: a intenção do popular no engajamento político. São Paulo: Perspectiva, 2004.

LEHMANN, Hans-Thies. Teatro pós-dramático. São Paulo: Cosac Naify, 2007.

PISCATOR, Erwin. Teatro político. Rio de Janeiro: Civilização Brasileira, 1968.

RANCIÈRE, Jacques. A partilha do sensível: estética e política. São Paulo: EXO experimental, 2005

SARRAZAC, Jean-Pierre. Realismo e encenação moderna: o trabalho de André Antoine". In: CARVALHO, Sérgio de (Org.). O teatro e a cidade: lições de História do Teatro. São Paulo: SMC, 2004. 